\title{
12 Lead ECG Extracted From 12 Lead Continuous ECG Recording
}

National Cancer Institute

\section{Source}

National Cancer Institute. 12 Lead ECG Extracted From 12 Lead Continuous ECG

Recording. NCl Thesaurus. Code C123445.

Any electrocardiogram (ECG) reading excerpted from a continuous, 12 Lead ECG. 